\title{
Rheology, Mechanical Properties, and Thermal Stability of Maleated Polyethylene Filled with Nanoclays
}

\author{
Abdulhadi A. Al-Juhani \\ Department of Chemical Engineering, King Fahd University of Petroleum \& Minerals (KFUPM), P.O. Box 68, \\ Dhahran 31261, Saudi Arabia \\ Correspondence should be addressed to Abdulhadi A. Al-Juhani; aljuhani@kfupm.edu.sa
}

Received 1 August 2015; Revised 28 September 2015; Accepted 20 October 2015

Academic Editor: Yibing Cai

Copyright (C) 2015 Abdulhadi A. Al-Juhani. This is an open access article distributed under the Creative Commons Attribution License, which permits unrestricted use, distribution, and reproduction in any medium, provided the original work is properly cited.

\begin{abstract}
Maleated polyethylene (MAPE) was used in this study as a model matrix for hosting hydrophobic nanoclay (C15A) and hydrophilic nanoclay (C30B), to investigate the effect of nanoclay loading on the bulk properties of the composites. Composites were prepared by melt-blending technique, with varying the loading from 0 to $9 \mathrm{wt}$.\%. Tensile, oxidative TGA, and FE-SEM tests were employed for both C15A-filled polymer and C30B-filled polymer, which confirmed that C15A had better dispersion and was much superior to $\mathrm{C} 30 \mathrm{~B}$ for enhancing the mechanical properties and thermal stability of MAPE. Consequently, XRD and melt rheology tests were performed for C15A-filled polymer only. XRD confirmed the formation of nanocomposite structure, which could be the main reason for the significant increase in the thermal stability and viscosity. For example, compared to the neat polymer, the degradation temperature at the $20 \%$ mass loss was increased by $72^{\circ} \mathrm{C}$ after the addition of $5 \mathrm{wt} . \% \mathrm{C} 15 \mathrm{~A}$. Based on rheological analysis, the percolation threshold was around $3 \mathrm{wt}$ \% loading of C15A. Fitting the viscosity data to the Cross model suggested that increasing C15A loading had a strong effect for increasing the shear thinning index and relaxation time of the nanocomposites.
\end{abstract}

\section{Introduction}

Polymer nanocomposites are materials where a small amount of nanofillers is added to a polymer matrix [1]. Owing to the high surface area of the nanofillers, the expectation is that this addition would cause a dramatic improvement in the bulk properties of the composites prepared. However, this improvement is highly dependent on the level of dispersion of the nanofillers inside the host matrix and on the nanofillers/matrix adhesion $[2,3]$. Therefore, more systematic works are needed to study the structure-property relationships of these exciting advanced materials.

Nanoclay is plate-like material with thickness in the nanoscale. The wet chemistry is now well established to modify the surface of nanoclays with several types of organic modifiers [4]. Nanoclays are now available commercially in cheap values, making them a promising filler candidate in the polymer composite industry for diverse end-uses $[5,6]$. The property enhancement in polymers by adding nanoclays had been confirmed by several studies, such as mechanical property improvement for nylon 6 [7], fire resistance property enhancement for polystyrene [8], and oxygen-barrier property enlargement for poly(ethylene terephthalate) [9].

Polyethylene is the most commodity thermoplastic available commercially and used worldwide for wide applications [10]. Pure "unfunctionalized" polyethylene as the only host matrix for nanoclays without the addition of external compatibilizers had been the subject of extensive research [11-13]. Due to the fact that polyethylene is highly nonpolar in nature, melt-blending of polyethylene with unmodified hydrophilic nanoclays would result in rather microcomposite formation. However, even though if nanoclays were modified with long nonpolar alkyl chains similar in structure to polyethylene chains, previous results showed that nanocomposite formation was difficult and the mechanical properties obtained were low compared to the neat polymer [13]. This could be due to the absence of special attractive interactions such as hydrogen bonding between the filler and the polymer.

In order to increase the attractive interactions between organically modified nanoclays and polyethylene, functionalized polyethylene with a polar functional group was usually 
added to the system as a compatibilizing agent. One example of functionalized polyethylene was maleated polyethylene, which was polyethylene grafted with maleic anhydride functional group. Maleated polyethylene had been widely studied in research as a compatibilizing agent for improving the dispersion of different microfillers and nanofillers such as fly ash [14], carbon nanotubes [15], and nanoclays [16] in polyethylene matrix. The above studies confirmed the importance of having MAPE as compatibilizer for improving the dispersion and properties of polyethylene composites.

However, a few studies [17-22] were published for examining the case of using maleated polyethylene as the only host matrix for the nanoclays used without adding unfunctionalized polyethylene to the mixture. In our previous study [11], a binary system made of very low loading of nanoclays (less than $0.1 \mathrm{wt} . \%$ ) and unfunctionalized polyethylene as the matrix was considered for the purpose of studying the effect of nanoclay on the enhancement of extrusion of polyethylene. In another study [16], we reported the thermal and dynamic mechanical properties of a ternary system made of nanoclay as the filler (maximum loading was $5 \mathrm{wt} . \%$ ), unfunctionalized polyethylene as the main matrix, and maleated polyethylene as a compatibilizer.

Therefore, the purpose of this current study was to examine the structure and properties of a model binary system which consisted only of maleic anhydride-grafted high density polyethylene (MAPE) as the only matrix and nanoclays as the filler (loading up to $9 \mathrm{wt} . \%$ ) without the addition of any third component. Two types of organically modified nanoclays were selected, one with the most hydrophobic nature $(\mathrm{C} 15 \mathrm{~A})$ and one with the most hydrophilic nature $(\mathrm{C} 30 \mathrm{~B})$, in order to examine the effect of the nanoclay loading and type on the bulk properties of the nanocomposites prepared. First, tensile mechanical test, oxidative thermal stability test, and Field Emission Scanning Electron Microscopy (FE-SEM) test were performed for both types of nanoclays. Subsequently, XRay Diffraction (XRD) and rheological tests were performed only for the nanoclay type with superior mechanical and thermal stability behavior.

The expected findings of this study could be useful for identifying which formulations (C15A-filled MAPE or C30B-filled MAPE) need to be used as a masterbatch to be mixed later in the future with conventional polyethylene in order to obtain materials with superior mechanical and thermal properties. Moreover, the melt rheological properties reported here for the masterbatch could be utilized in the future for modeling and optimizing the melt-processing conditions of nanoclay-filled polyethylene composites.

\section{Materials and Methods}

2.1. Materials. Maleated polyethylene used was a commercial grade (Polybond 3009) obtained from Chemtura. It was a maleic anhydride-grafted high density polyethylene (MAPE), with MA level of $1 \mathrm{wt} . \%$, melt flow rate of $5 \mathrm{~g} / 10 \mathrm{~min}$ at $190^{\circ} \mathrm{C}$, and a density of $0.95 \mathrm{~g} / \mathrm{cm}^{3}$ at room temperature. Two distinct types of nanoclays were used: Cloisite 15A (C15A) and Cloisite 30B (C30B); both were obtained from Southern Clay Products, Inc., USA. C15A had its surface organically modified by a hydrophobic group (dimethyl dehydrogenated tallow ammonium), whereas C30B had its surface organically modified by a hydrophilic $\mathrm{OH}$ group (methyl tallow dihydroxyethyl quaternary ammonium). The concentration of the organic modifier for $\mathrm{C} 15 \mathrm{~A}$ and $\mathrm{C} 30 \mathrm{~B}$ was 125 and 90 meq/100 g clay, respectively. The density of C15A and C30B was $1.66 \mathrm{~g} / \mathrm{cm}^{3}$ and $1.98 \mathrm{~g} / \mathrm{cm}^{3}$, respectively.

2.2. Composites Preparation. All batches were prepared by melt-blending technique using HAAKE PolyDrive machine with a capacity of $40 \mathrm{~g}$ per batch. The melt-blending temperature, time, and rotational speeds were $170^{\circ} \mathrm{C}, 10 \mathrm{~min}$, and $60 \mathrm{rpm}$, respectively. First, control maleated polyethylene (MAPE) sample without nanofillers was prepared. Second, MAPE samples filled with 1, 3, 5, 7, and 9 wt.\% loadings of C15A nanoclay were prepared. Third, MAPE samples filled with $1,3,5,7$, and 9 wt. $\%$ loadings of C30B nanoclay were also prepared.

2.3. Mechanical Testing. Tensile mechanical testing was applied for control unfilled MAPE polymer and its composites filled with nanoclays of both types (C15A and C30B). Carver Hydraulic Press machine was used to prepare specimens for mechanical testing according to ASTM D638 by melting the samples at $170^{\circ} \mathrm{C}$ and applying a pressure range of $0-5$ tons and using a total pressing duration of $7 \mathrm{~min}$. The specimens were then allowed to cool for $5 \mathrm{~min}$. The dogshape specimens were then subjected to tensile testing by the Instron 5567 machine at a crosshead speed of $10 \mathrm{~mm} / \mathrm{min}$ and at room temperature. The data reported for each composition was the average of 5 specimens.

2.4. TGA Testing. The oxidative thermal stability of the C15A/MAPE and C30B/MAPE samples was examined by Thermogravimetric Analysis (TGA) under air environment using TA Instrument (model: SDT Q600). Around $8 \mathrm{mg}$ of the samples were scanned in the temperature range of $25^{\circ} \mathrm{C}$ to $700^{\circ} \mathrm{C}$, with a heating rate of $10^{\circ} \mathrm{C} / \mathrm{min}$ and a flow rate of air of $100 \mathrm{~cm}^{3} / \mathrm{min}$.

2.5. Morphology Testing. The morphology of the C15A-filled polymer samples of all loadings was inspected by X-Ray Diffraction (XRD) at room temperature using a reflection mode. XRD was also applied for control C15A powder for comparison. XRD patterns were generated using $\mathrm{Cu}$ $\mathrm{K} \alpha$ radiation $(\lambda=0.154 \mathrm{~nm}$; voltage $=40.0 \mathrm{kV}$; current $=$ $30.0 \mathrm{~mA}$ ). The scan range for $2 \theta$ was varied from $3^{\circ}$ to $10^{\circ}$, with an interval of $0.02^{\circ}$ and scan rate of $0.5^{\circ} / \mathrm{min}$.

In addition to XRD testing, the morphology of all filled samples of both types of nanoclays (C15A and C30B) was further examined by Field Emission Scanning Electron Microscopy (FE-SEM) (model: MIRA 3 LMU, from TESCAN), with an applied accelerating electron voltage of $15 \mathrm{kV}$. Prior to FE-SEM examination, the samples were subjected to cryogenic fracture using liquid nitrogen followed by coating the fractured surfaces with a thin $5 \mathrm{~nm}$ layer of platinum to avoid charging effect during the imaging. 
2.6. Rheology Testing. The melt rheological behavior of the C15A-filled polymer samples of all loadings was examined by Advanced Rheometric Expansion System (ARES) equipment. Ring-shape specimens with diameter of $20 \mathrm{~mm}$ and thickness of around $1 \mathrm{~mm}$ were obtained from the prepared batches and subjected to ARES testing. All runs were done at a temperature of $170^{\circ} \mathrm{C}$ and cone-and-plate geometry. Dynamic testing mode in the linear viscoelastic region was applied at shear strain amplitude $\left(\gamma_{o}\right)$ of $10 \%$. The angular frequency $(\omega)$ was varied from 0.01 to $100 \mathrm{~s}^{-1}$. All runs were performed under nitrogen gas environment. More details for the ARSE equipment and procedures and the theoretical background for the material functions measured were described elsewhere [23].

\section{Results and Discussion}

3.1. Mechanical Properties. The effects of nanoclay loading and nanoclay type on the elastic modulus of the composites were shown in Figure 1. For the case of C15A nanoclay, the elastic modulus gradually increased as the loading of C15A increased up to $9 \mathrm{wt} . \%$ loading. However, for the case of $\mathrm{C} 30 \mathrm{~B}$, the elastic modulus slightly increased as the loading of C30B increased up to $5 \mathrm{wt} . \%$ loading, and then there was a slight decrease at $7 \mathrm{wt} . \%$ loading. Moreover, at any particular loading, the hydrophobic C15A nanoclay was more effective for increasing the modulus of the composites compared to the hydrophilic $\mathrm{C} 30 \mathrm{~B}$ nanoclay. For example, relative to the unfilled sample, the \% enhancement in the elastic modulus of 7 wt.\% C15A/MAPE systems was $72 \%$ enhancement, whereas it was only $25 \%$ enhancement for the $7 \mathrm{wt} . \%$ C30B/MAPE system. This was an indication that C15A nanoclay had better dispersion in the host matrix compared to C30B nanoclay, and consequently better stress transfer could be proposed for the C15A/MAPE system.

The organic modifier for C15A had two sides of long alkyl chains, where the number of carbon was between 16 and 18. This would help enlarge the spacing between sheets of the nanoclays which helped the polyethylene chains to penetrate easier during the melt-blending process. In addition, mechanical interlocking would be expected between the polyethylene chains and the long alkyl chains of the C15A modifier which would assist in improving the dispersion. On the other hand, the organic modifier for $\mathrm{C} 30 \mathrm{~B}$ contains two sides of short hydroxyethyl chains, where these short chains would not help a lot in increasing the spacing of nanoclays sheets and would not help in mechanical interlocking with the polyethylene chains.

Even though C15A nanoclay had its surface organically modified with long C18 alkyl chains, several studies confirmed that direct melt-blending of $\mathrm{C} 15 \mathrm{~A}$ with unfunctionalized polyethylene without the addition of compatibilizers (such as MAPE) did not result in nanocomposite formation [24]. One explanation was that hydrogen bonding between oxygen on the surface of nanoclays and the polar MA group of MAPE was possible which would assist the favorable interactions, whereas it was not possible between the unfunctionalized polyethylene and the surface of nanoclays.

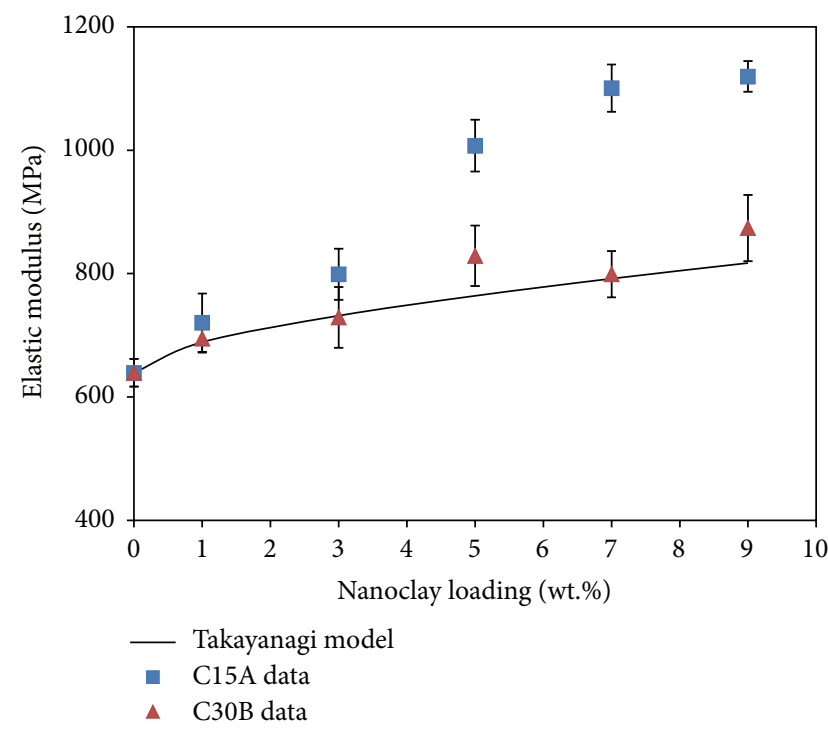

FIGURE 1: Effect of nanoclays loading and surface modification on the elastic modulus of MAPE matrix. The line was theoretical prediction according to Takayanagi model.

In an attempt to explain the tensile modulus data, they were fitted according to the Takayanagi model, which stated that [25]

$$
E_{c}=\frac{E_{p}}{\left[(1-\beta)+\beta /\left((1-\beta)+\beta E_{f} / E_{p}\right)\right]},
$$

where $E_{c}, E_{p}$, and $E_{f}$ were the elastic modulus of the composite, the pure polymer, and the filler, respectively. As suggested in literature [25], the elastic modulus of nanoclays $\left(E_{f}\right)$ was fixed at $178 \mathrm{GPa}$. The parameter $\beta$ was the square root of the volume fraction of the filler $\left(\phi_{f}\right)$, which was calculated as follows:

$$
\phi_{f}=\frac{\left(w_{f} / \rho_{f}\right)}{\left[\left(w_{f} / \rho_{f}\right)+\left(w_{p} / \rho_{p}\right)\right]},
$$

where $w_{f}$ and $w_{p}$ were the mass fraction of the filler and the pure polymer, respectively; $\rho_{f}$ and $\rho_{p}$ were the density of the filler and the pure polymer, respectively. Takayanagi model was derived based on the assumption that there was poor adhesion between the filler surface and the polymer matrix. As seen in Figure 1, there was a perfect fit between the model prediction and the $\mathrm{C} 30 \mathrm{~B}$ data, which proposed that there was poor adhesion between the $\mathrm{C} 30 \mathrm{~B}$ nanoclay and the MAPE polymer matrix. On the other hand, a good adhesion between the C15A nanoclay and the MAPE matrix was expected, which could explain the deviation between the model prediction and the C15A data.

The yield strength is another important mechanical property of polymer composites, which was often considered in literature to be more sensitive than the elastic modulus for quantifying the effect of filler-polymer interactions and the role of adhesion between the filler and the polymer [26]. As shown in Figure 2, the yield strength increased as the loading 


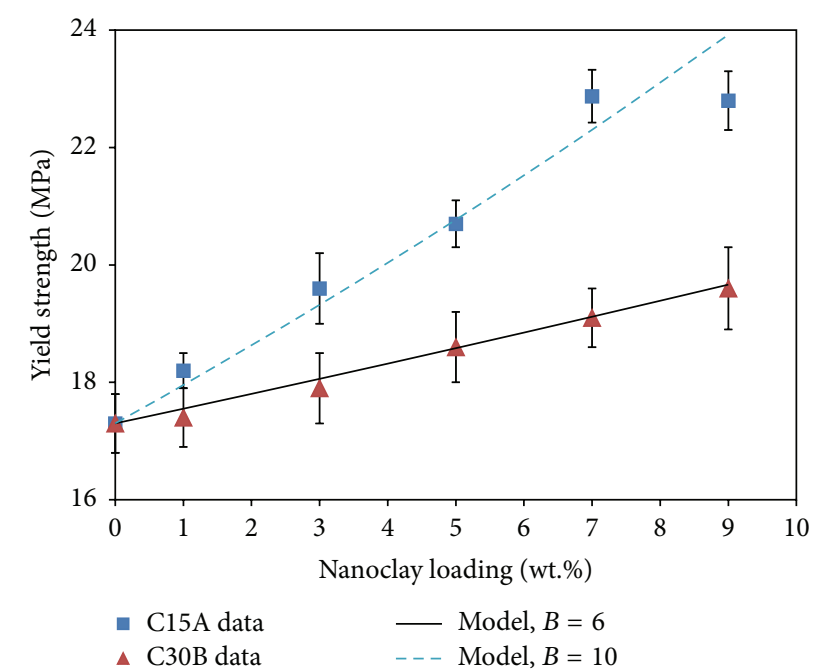

FIGURE 2: Effect of nanoclays loading and surface modification on the yield strength of MAPE matrix. The lines were theoretical predictions according to Pukanszky model.

of nanoclays increased, but the effect was more pronounced for the $\mathrm{C} 15 \mathrm{~A}$ type compared to the C30B type. For example, there was $32 \%$ enhancement for the yield strength of the $7 \mathrm{wt} . \% \mathrm{C} 15 \mathrm{~A} / \mathrm{MAPE}$ composite relative to the neat polymer, whereas there was was only $10 \%$ enhancement for the $7 \mathrm{wt} . \%$ C30B/MAPE composite. Again, the adhesion between the filler and the polymer could be the reason for this difference between $\mathrm{C} 15 \mathrm{~A}$ and $\mathrm{C} 30 \mathrm{~B}$ nanoclays. This could be understood more by fitting the data to the Pukanszky model, which stated that [25]

$$
\sigma_{c}=\sigma_{p}\left[\frac{\left(1-\phi_{f}\right)}{\left(1+2.5 \phi_{f}\right)}\right] \exp \left(B \phi_{f}\right),
$$

where $\sigma_{c}$ and $\sigma_{p}$ were the yield strength of the composite and the pure polymer, respectively. According to the Pukanszky model, the parameter $B$ was an empirical parameter lumping together all kinds of interfacial interactions between the filler surface and the polymer. Therefore, as the value of $B$ increased, the interfacial interactions and the adhesion strength between the filler and the matrix increased. As can be seen in Figure 2, the model fitting with the C30B data was adequate if $B$ was assigned a value of 6 , whereas the model prediction was in agreement with the C15A data if $B$ had a value of 10 . A higher value of $B$ indicated better adhesion between the C15A surface and the host polymer matrix compared to the $\mathrm{C} 30 \mathrm{~B}$ surface, as expected.

The tensile strength data followed the same trend, as shown in Figure 3. For C15A-filled system, the tensile strength steadily increased as the loading of $\mathrm{C} 15 \mathrm{~A}$ increased up to $7 \mathrm{wt} \%$ loading and then remained unchanged at $9 \mathrm{wt} . \% \mathrm{C} 15 \mathrm{~A}$ loading. However, for C30B-filled system, the tensile strength slightly increased as the loading of $\mathrm{C} 30 \mathrm{~B}$ increased up to 5 wt.\% loading, and then there was a slight decrease at 7 wt.\% loading. Moreover, at any particular loading, C15A nanoclay was more effective for the enhancement compared to C30B

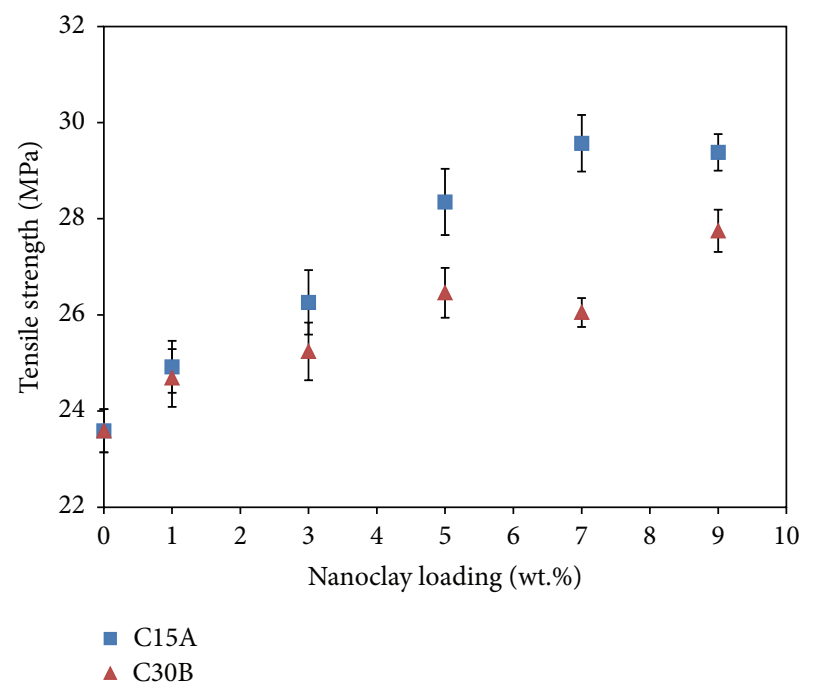

FIGURE 3: Effect of nanoclays loading and surface modification on the tensile strength of MAPE matrix.

nanoclay. For instance, relative to the unfilled sample, the \% enhancement in the tensile strength of $7 \mathrm{wt} . \%$ C15A/MAPE systems was $25 \%$, whereas it was only $10 \%$ enhancement for the $7 \mathrm{wt} . \% \mathrm{C} 30 \mathrm{~B} / \mathrm{MAPE}$ system. This was attributed to the better dispersion and adhesion for C15A type compared to $\mathrm{C} 30 \mathrm{~B}$, as discussed before.

3.2. Thermal Stability. TGA under air environment had been a popular and valuable technique for examining the effect of nanofillers on suppressing oxidative degradation of polymers. The cumulative weight and the derivative weight as function of temperature for the neat MAPE polymer and its C15Afilled nanocomposites were shown in Figures 4(a) and 4(b), respectively. Compared to the neat polymer, a significant shift in the degradation temperature was observed upon the addition of C15A nanoclays of all loadings. This was presented more clearly in Figure 5, where the degradation temperature was plotted as a function of nanoclays loading. For example, compared to the neat polymer, the degradation temperature at the $20 \%$ mass loss was increased by $72^{\circ} \mathrm{C}$ after the addition of $5 \mathrm{wt} . \%$ C15A. This could be attributed to the excellent dispersion of C15A nanoclay inside the MAPE matrix, which helped $\mathrm{C} 15 \mathrm{~A}$ nanoclay to act as a physical barrier against degradation of the MAPE matrix.

The enhancement in thermal stability could be due to the following reasons [27]. First, silicate layers were impermeable to gases and therefore decreased the permeation rate of the volatile products formed during decomposition. Second, silicate layers could act as heat insulator to the polymer matrix because of the formation of carbonaceous silicate chars on the clay surface, and these silicate chars could also act as adsorbing sites for the volatile products formed during decomposition.

Oxidative TGA were also performed for C30B/MAPE samples and compared with C15A/MAPE samples, as shown in Figure 5. It was interesting to notice that, at any particular 


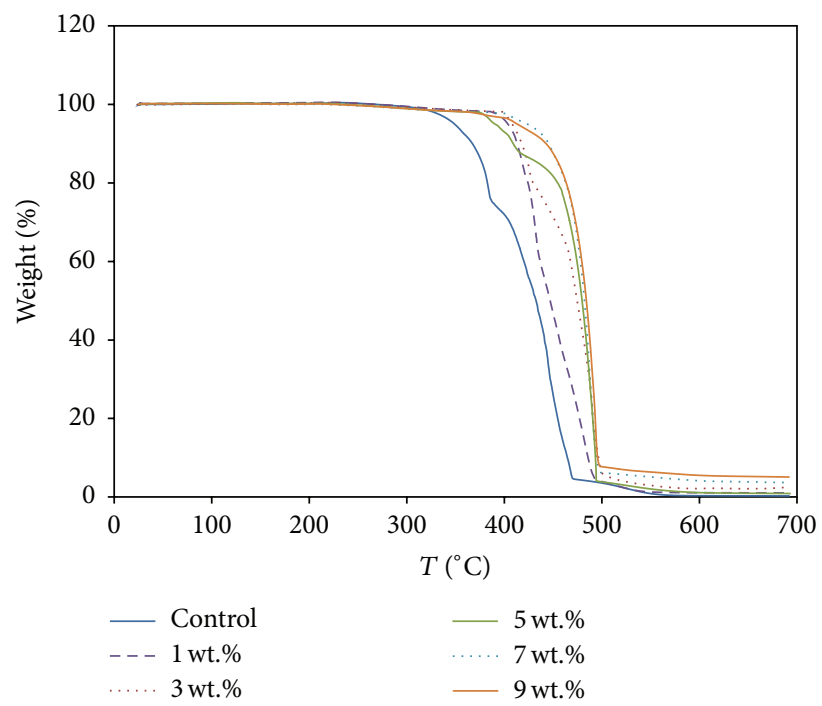

(a)

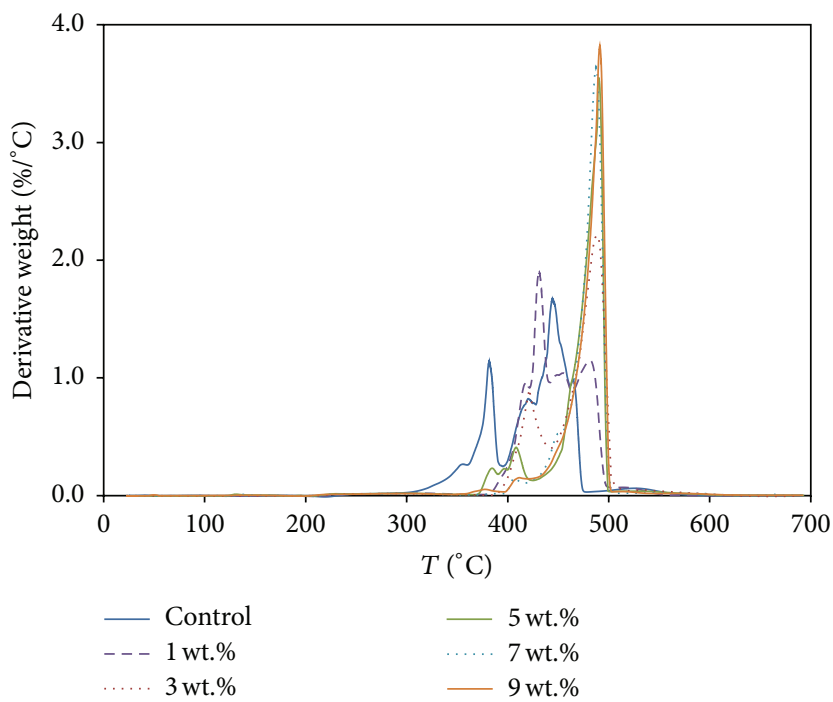

(b)

FIGURE 4: (a) TGA and (b) DGA results under air environment for pure MAPE matrix (control) and its respective nanocomposites filled with C15A nanoclay with different loadings.

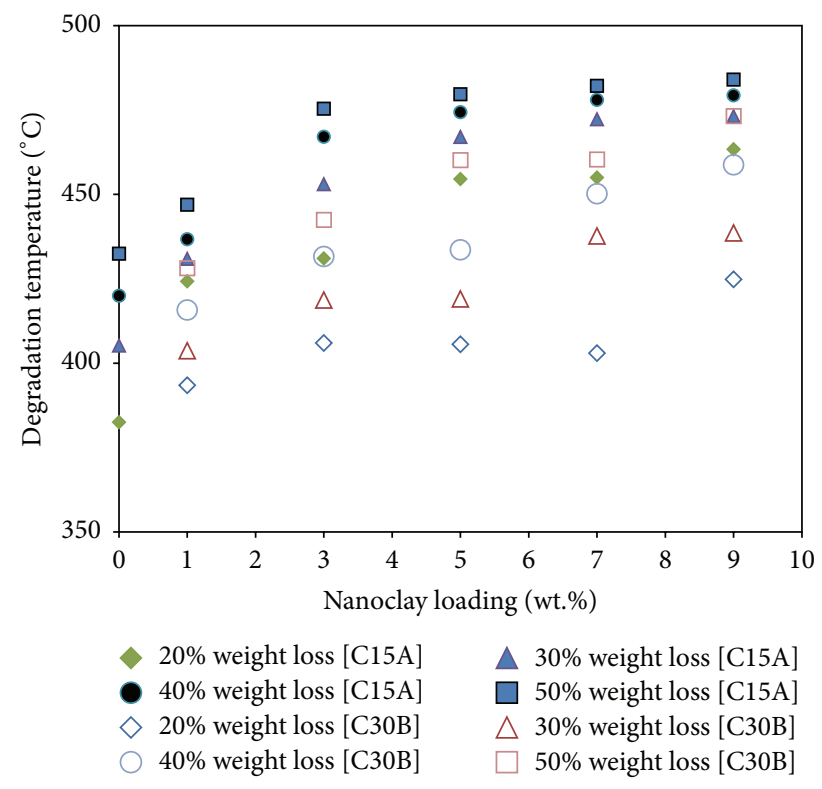

FIGURE 5: Effect of nanoclay loading and type on the oxidative degradation temperature of MAPE matrix. The $20 \%$ weight loss data were defined as temperature where $20 \%$ of the initial mass of the sample disappeared and similarly for other curves. Filled symbols were for C15A nanoclay type, whereas unfilled symbols were for C30B nanoclay type.

loading, C15A nanoclay was more effective than C30B nanoclay for increasing the thermal stability of MAPE matrix. For example, the degradation temperatures at the $20 \%$ mass loss were $454.6^{\circ} \mathrm{C}$ and $405.6^{\circ} \mathrm{C}$ for the 5 wt. $\%$ C15A/MAPE and 5 wt.\% C30B/MAPE samples, respectively.

Since both tensile mechanical properties data and oxidative TGA data confirmed that C15A type was more useful

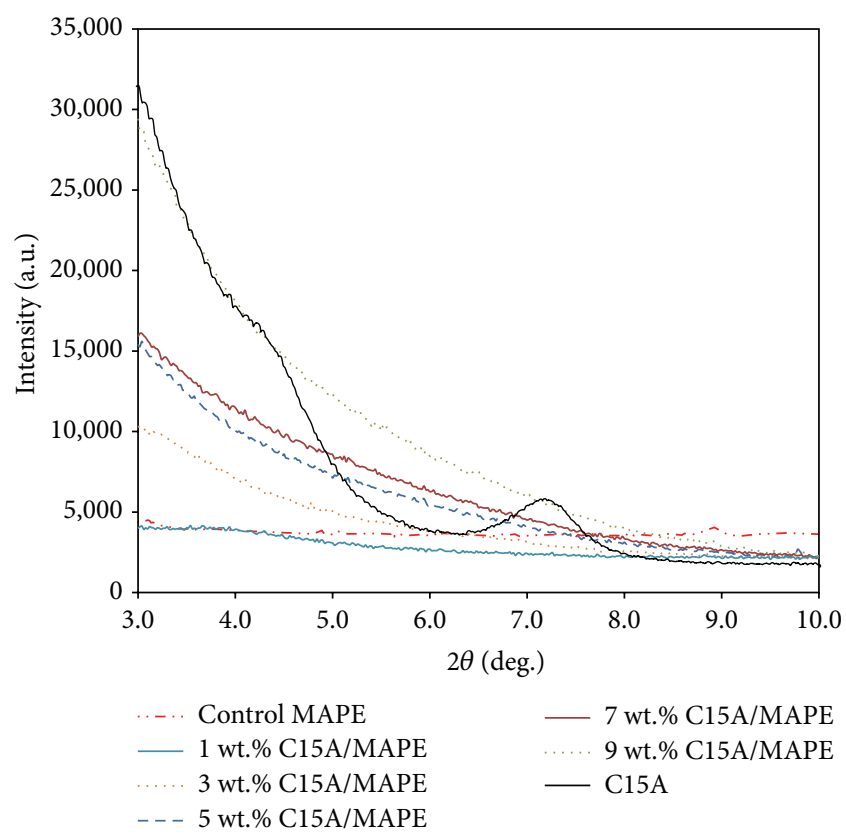

FIGURE 6: XRD patterns of C15A clay powder and MAPE matrix filled with $\mathrm{C} 15 \mathrm{~A}$ of different loadings.

than C30B type for enhancing the mechanical properties and oxidative thermal stability of MAPE matrix, it was decided to consider only the C15A type for subsequent $\mathrm{XRD}$ and rheological characterizations.

3.3. Morphology Characterization. XRD had been a nondestructive test for probing the morphology of nanoclays inside the host polymer matrix. The XRD patterns for all C15A-filled MAPE samples of different loadings were shown in Figure 6 
and compared with the XRD pattern for the control C15A powder. A clear peak was observed for the control C15A powder at $2 \theta$ of about $7.18^{\circ}$, whereas no peaks were observed for the C15A-filled MAPE samples of different loadings. According to literature [28], the absence of a significant peak for the filled sample was a signature for nanocomposite formation. The excellent dispersion suggested by XRD for C15A inside the MAPE matrix was believed to be the main reason for mechanical properties and thermal stability enhancement observed for the C15A/MAPE nanocomposites.

In addition, the morphology of all MAPE-filled samples of both types of nanoclays (C15A nanoclay and C30B nanoclay) was further examined by Field Emission Scanning Electron Microscopy (FE-SEM). Figure 7 demonstrated representative FE-SEM micrographs for $1 \mathrm{wt} . \%$ loading, $5 \mathrm{wt} . \%$ loading, and 9 wt.\% loading for C15A-filled and C30B-filled samples. As can be observed in Figure 7, C15A nanoclay had better dispersion in MAPE matrix compared to C30B nanoclay.

3.4. Rheological Properties. The storage modulus $\left(G^{\prime}\right)$ and the loss modulus $\left(G^{\prime \prime}\right)$ of the nanocomposites as function of frequency and C15A loading were shown in Figures 8 and 9, respectively. As shown in Figures 8 and $9, G^{\prime}$ and $G^{\prime \prime}$ increased as frequency decreased and $\mathrm{C} 15 \mathrm{~A}$ loading increased for all samples. For a viscoelastic material such as filled polymer melts, $G^{\prime}$ reflected the "solid-like" part, whereas $G^{\prime \prime}$ reproduced the "liquid-like" part of that material $[6,28]$. By comparing Figure 8 with Figure 9, it was observed that $G^{\prime}$ had a stronger C15A loading dependency than $G^{\prime \prime}$, especially at low frequency range $\left(\omega \leq 0.1 \mathrm{~s}^{-1}\right)$. Therefore, this fact had been utilized here to estimate the percolation threshold of C15A inside the MAPE matrix. The percolation threshold was defined here as the minimum loading of $\mathrm{C} 15 \mathrm{~A}$ to form an interconnected physical network inside the host polymer matrix. It was a common practice in literature to quantify the percolation concentration of filler by simply observing the plateau in the elastic modulus $\left(G^{\prime}\right)$ at low frequency region [29]. Empirically, it was determined here by calculating the slope of a power law fit to $G^{\prime}$ data in the low frequency range $\left(\omega \leq 0.1 \mathrm{~s}^{-1}\right)$ for a particular $\mathrm{C} 15 \mathrm{~A}$ loading, as shown in Figure 10. Then, the slopes were plotted as function of C15 loading, as shown in Figure 11. Consequently, as shown in Figure 11, the sharp change in the slope of the linear fitting to the data occurred at the percolation threshold, which was here about $3 \mathrm{wt} . \%$ C15A. This method for estimating the percolation threshold was suggested and implemented by different investigators for several polymeric nanocomposites [30].

The percolation threshold could also be deduced by inspecting Van Gurp-Palmen plot, as suggested in literature [31]. In this method, shown in Figure 12 for the current study, the shift angle $(\delta)$ was plotted against the complex modulus $\left(G^{*}\right)$ for the various C15A loadings, and the change in the trend was examined. As shown in Figure 12, for the neat MAPE polymer as well as the $1 \mathrm{wt} . \% \mathrm{C} 15 \mathrm{~A} / \mathrm{MAPE}$ composite, $\delta$ decreased as $G^{*}$ increased with no formation of a maximum point, indicating no structural change could happen and hence no formation of a network of C15A could happen at $1 \mathrm{wt} . \%$ loading. On the other hand, noticeable maximum points were observed for the samples filled with $3 \mathrm{wt} . \% \mathrm{C} 15 \mathrm{~A}$ and higher loadings, indicating strong structural change occurred due to the formation of interconnected network of C15A.

The conclusion from Van Gurp-Palmen plot (Figure 12) was also in agreement with the plot of $\tan (\delta)$ as a function $\omega$ (Figure 13). As shown in Figure 13 for the low frequency range ( $\omega$ less than $\left.0.1 \mathrm{~s}^{-1}\right), \tan (\delta)$ decreased as $\omega$ increased for the neat polymer as well as the $1 \mathrm{wt} . \% \mathrm{C15A} / \mathrm{MAPE}$ sample, with a value of $\tan (\delta)$ much larger than 1 . This was a common feature of viscous polymer melt or a polymer melt filled with solid fillers below the percolation threshold. However, for higher loading samples starting form $3 \mathrm{wt} . \%$ and above, $\tan (\delta)$ increased as $\omega$ increased for the low frequency range ( $\omega$ less than $0.1 \mathrm{~s}^{-1}$ ), with a value of $\tan (\delta)$ close to or less than 1. This was a common attribute of a "gel" like material [32], which could be attributed to the formation of $\mathrm{C} 15 \mathrm{~A}$ networks at $3 \mathrm{wt} . \%$ and above loadings.

Although nanoclays do not conduct electricity, the methodology described above for estimating the rheological percolation threshold could be applied also to conductive nanofillers such as carbon nanotubes (CNT), where it was reported in literature that the rheological percolation threshold was in good agreement with the electrical percolation threshold for several systems such as CNT-filled polycarbonate system [33].

In summary, we found that the rheological percolation threshold for the C15A-filled maleated polyethylene system was around $3 \mathrm{wt} . \%$ loading. This was in agreement with Reddy et al. [22], where they found that the rheological percolation threshold was around $3 \mathrm{wt} . \%$ for their C15Afilled LDPE system compatibilized by maleated polyethylene. It was, however, in disagreement with the work of Sadeghipour et al. [12], where they filled unfunctionalized HDPE with C20A nanoclays without adding compatibilizers, where $\mathrm{C} 20 \mathrm{~A}$ and $\mathrm{C} 15 \mathrm{~A}$ were essentially having the same chemical structure of organic modifier. Even though they increased the loading of $\mathrm{C} 20 \mathrm{~A}$ up to $10 \mathrm{wt} . \%$, they did not observe plateau values for $G^{\prime}$ at low frequency range for all samples, indicating that there was no network formation for their system.

The complex viscosity $\left(\eta^{*}\right)$ of the nanocomposites as a function of frequency and nanoclay loading was shown in Figure 14. As the frequency increased, the complex viscosity decreased for both unfilled samples and samples filled with C15A nanoclay. In addition, the complex viscosity increased significantly as the loading of $\mathrm{C} 15 \mathrm{~A}$ increased for the entire frequency range.

In order to examine the effect of $\mathrm{C} 15 \mathrm{~A}$ loading on the shear thinning behavior of the MAPE matrix, $\eta^{*}$ was fitted according to the power law model, which stated that $[23,34]$

$$
\eta^{*}=K(\omega)^{-n},
$$

where $n$ was the shear thinning index. Ideally, $n$ had a value of 0 for a perfect Newtonian fluid. The power law model parameters were summarized in Table 1. $R^{2}$ values were above 


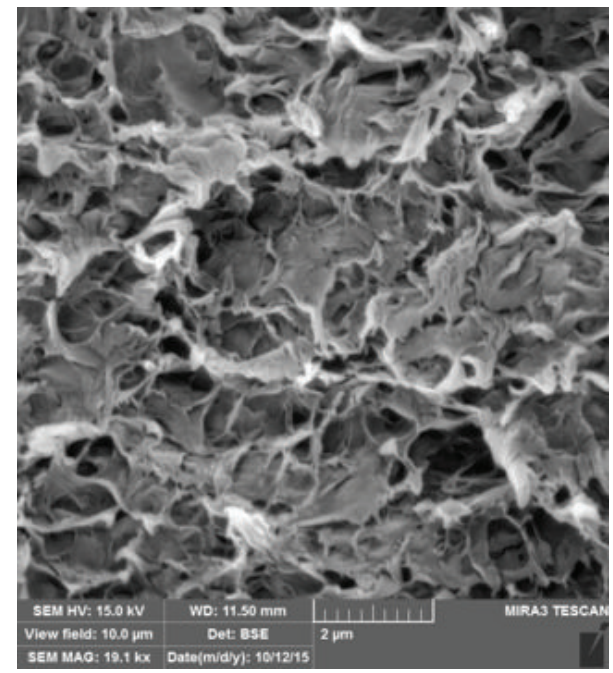

(a)

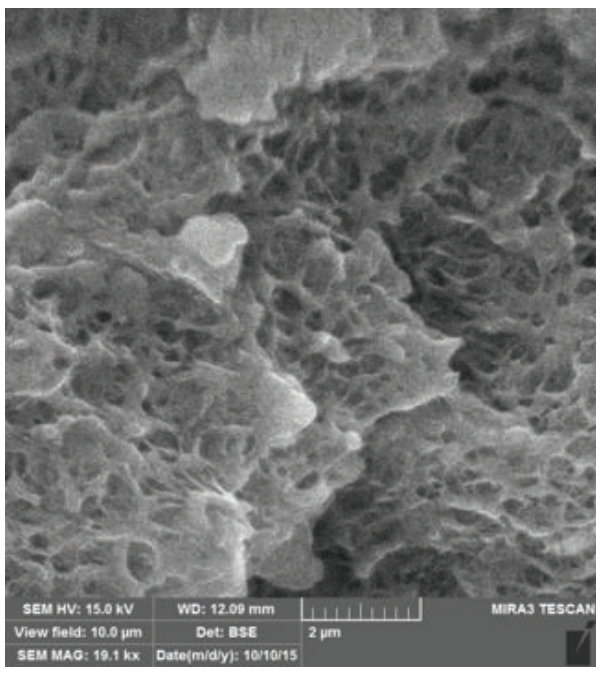

(c)

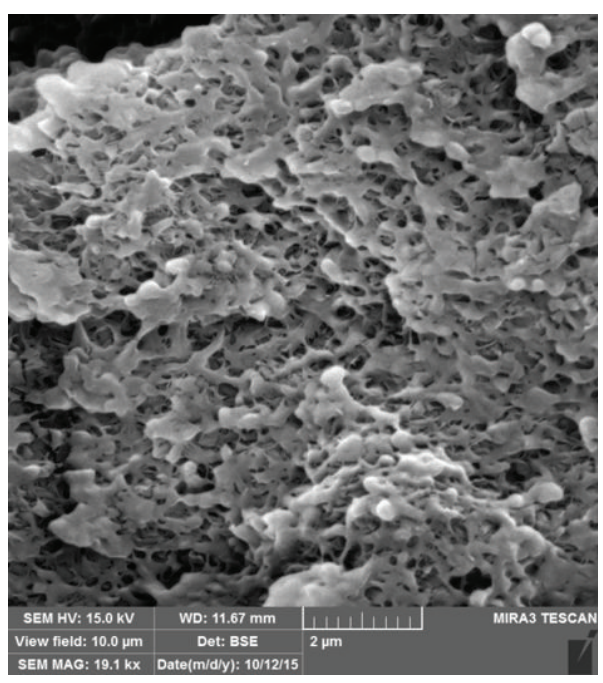

(e)

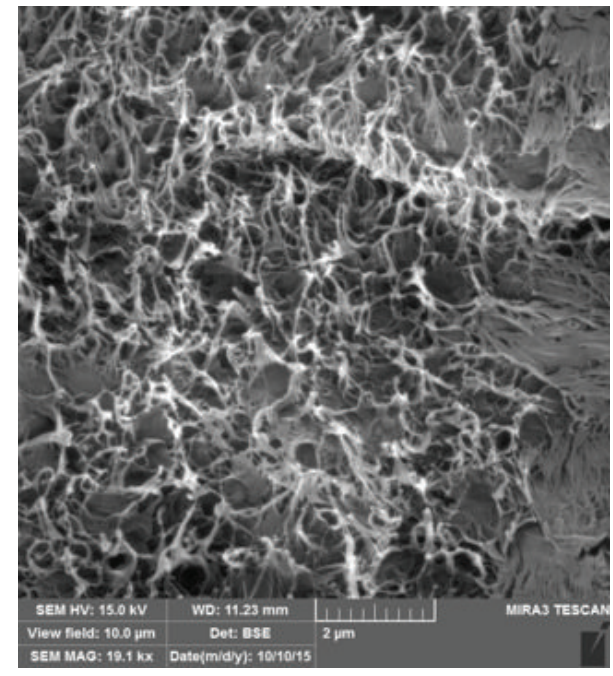

(b)

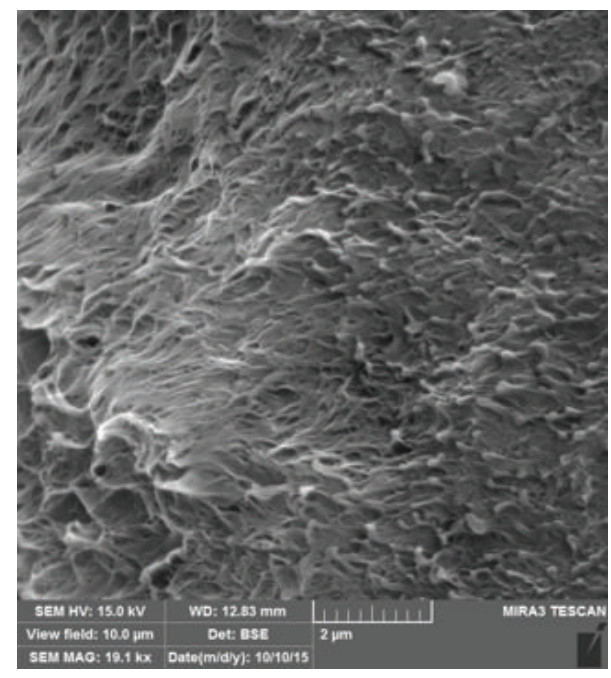

(d)

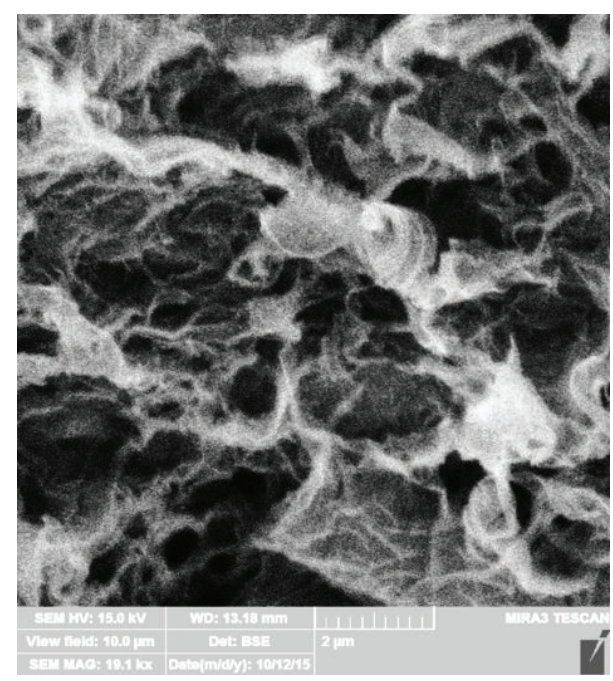

(f)

Figure 7: FE-SEM micrographs of (a) 1wt.\% C15A-filled MAPE, (b) 1 wt.\% C30B-filled MAPE, (c) 5 wt.\% C15A-filled MAPE, (d) 5 wt.\% C30B-filled MAPE, (e) 9 wt.\% C15A-filled MAPE, and (f) 9 wt.\% C30B-filled MAPE. 


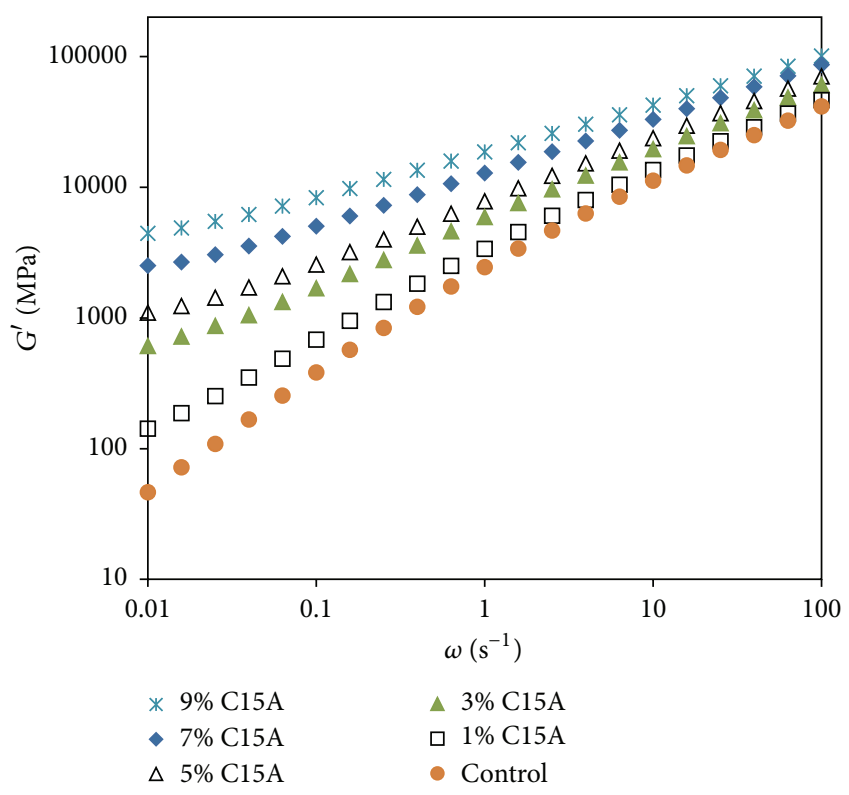

FIGURE 8: Effect of angular frequency and C15A nanoclay loading on the storage modulus of MAPE matrix (control).

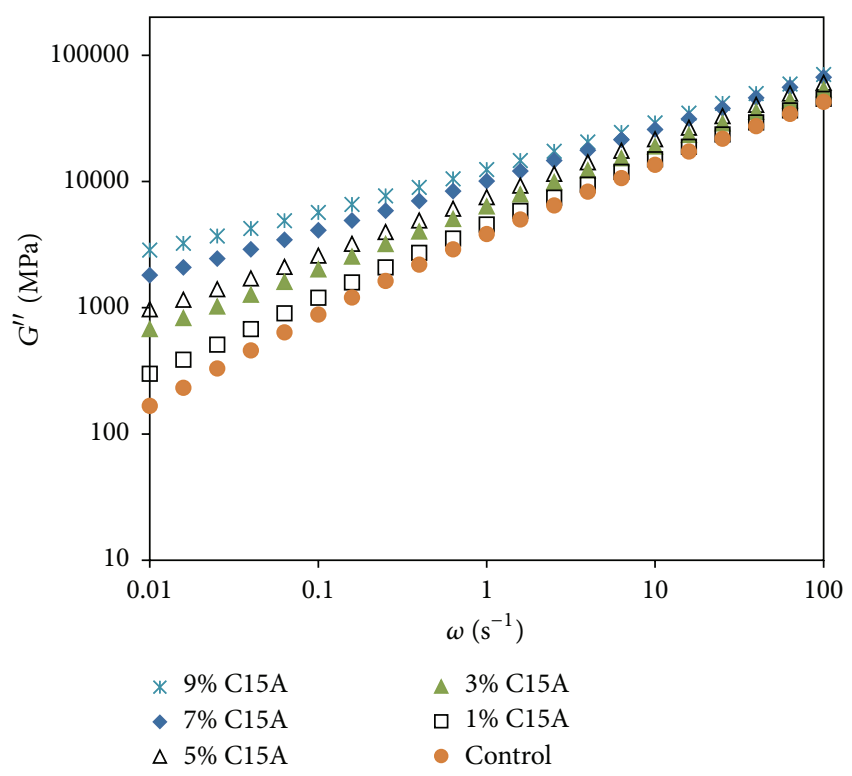

FIGURE 9: Effect of angular frequency and C15A nanoclay loading on the loss modulus of MAPE matrix (control).

0.99 , suggesting that there was an excellent fit between the data and the model for the range of $\omega$ considered ( 0.1 to $\left.10 \mathrm{~s}^{-1}\right)$. As shown in Table 1, $n$ was gradually increased from a value of 0.370 for the neat polymer to a value of 0.646 for the 9 wt.\% C15A/MAPE composite, suggesting that the presence of C15A had a strong effect for increasing the shear thinning of the MAPE polymer.

Regardless of its simplicity, the power law model was not adequate for fitting the viscosity data for the entire frequency range and it could not give extra information other than the

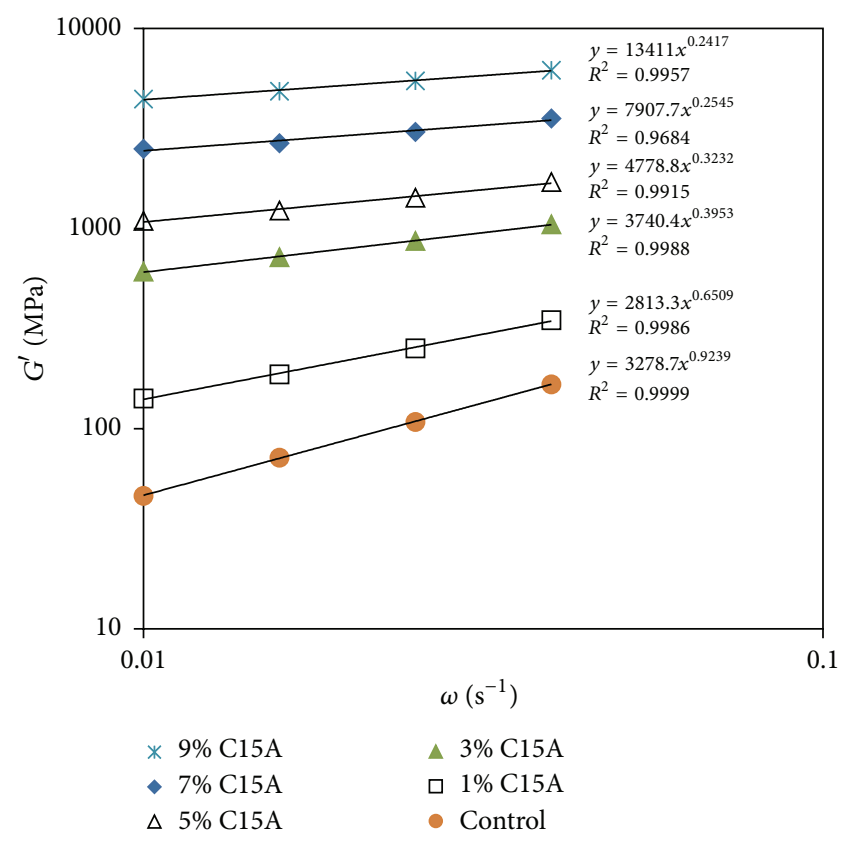

FIgURE 10: Low frequency dependence of the storage modulus for MAPE matrix (control) and its nanocomposites filled with C15A of different loadings. Discrete points were experimental data, and lines were power law fitting, with the fitting equations shown in the right side of the figure.

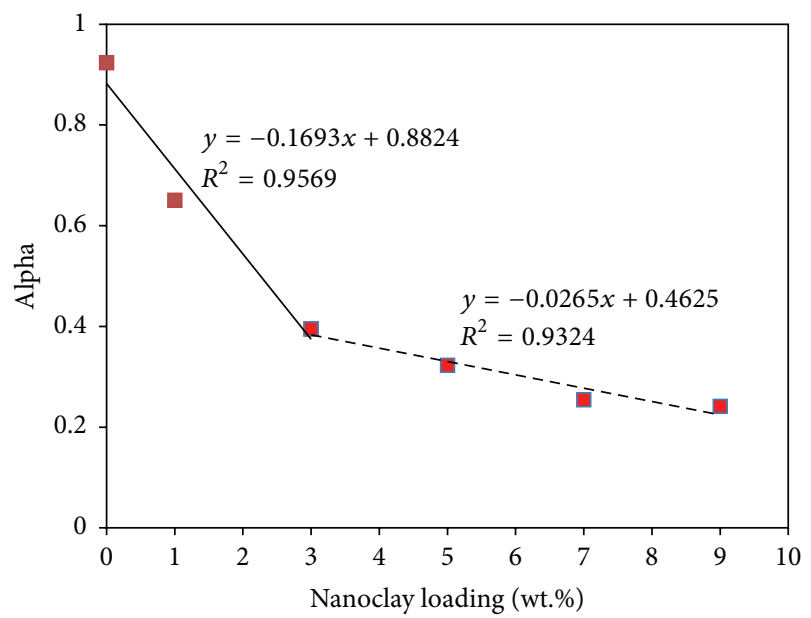

Figure 11: Percolation threshold of MAPE nanocomposites filled with C15A nanoclay. In $y$-axis, alpha was defined as the power law slop at low frequency range (less than $0.11 / \mathrm{s}$ ) of $\log G^{\prime}$ versus $\log \omega$ (i.e., alpha was the exponents of the fitting equations shown in Figure 10).

shear thinning index. Therefore, $\eta^{*}$ was fitted according to the Cross model, which stated that [34]

$$
\eta^{*}=\eta_{\infty}+\frac{\left(\eta_{o}-\eta_{\infty}\right)}{\left[1+(\lambda \omega)^{m}\right]}
$$

where $m$ was the shear thinning index, and $\lambda$ was the relaxation time. The parameters $\eta_{\infty}$ and $\eta_{o}$ were two empirical parameters that referred to the viscosity at very high $\omega$ and 


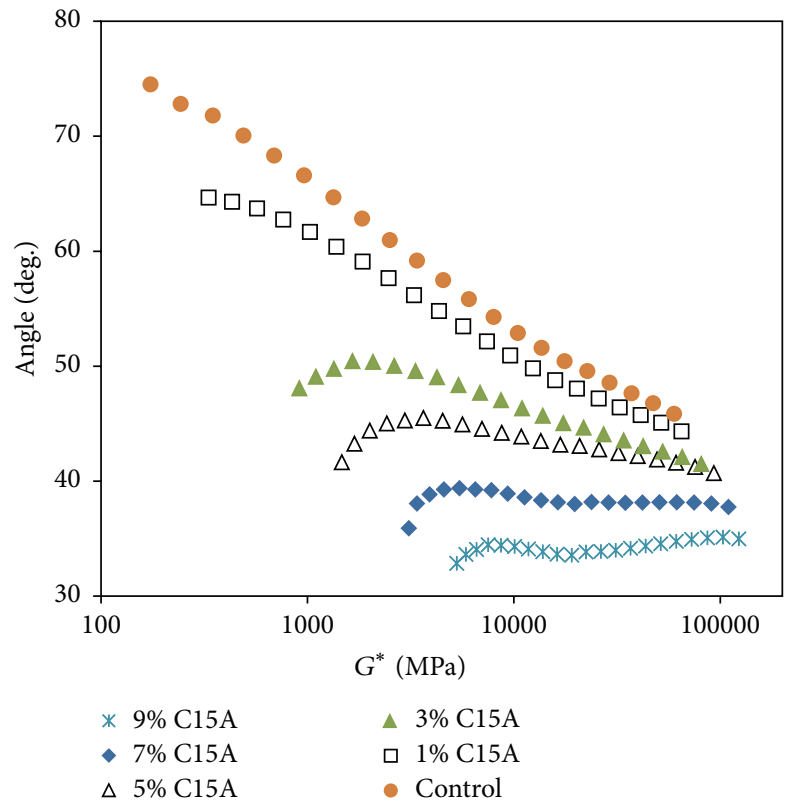

FIGURE 12: Van Gurp-Palmen plots for MAPE matrix (control) filled with C15A nanoclay of different loadings.

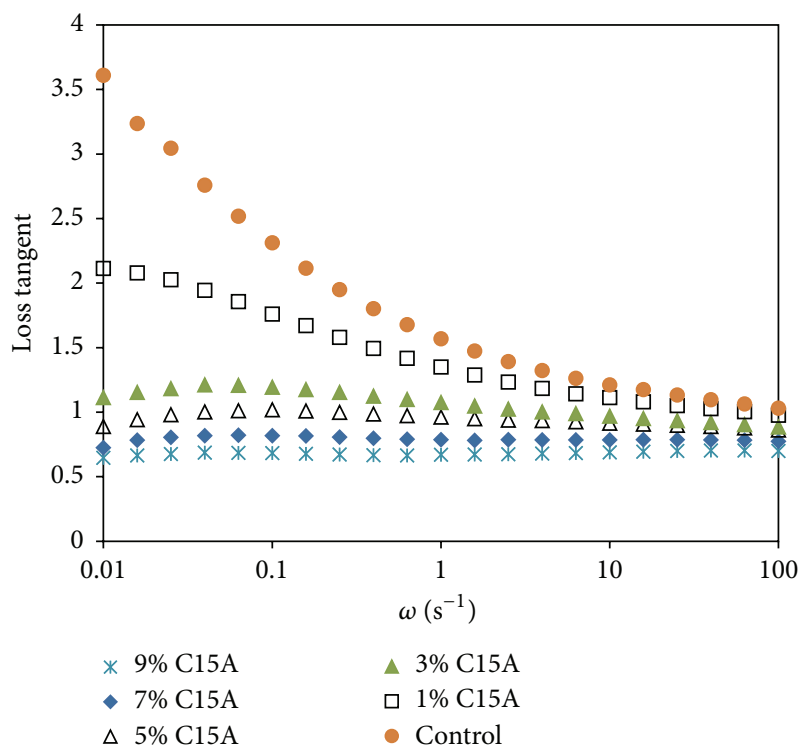

FIGURE 13: Effect of angular frequency $(\omega)$ and C15A nanoclay loading on loss tangent $(\tan \delta)$ of MAPE matrix (control).

very low $\omega$, respectively. In the present study, $\eta_{o}$ was estimated by extrapolating at $\omega$ value of $0.001 \mathrm{~s}^{-1}$ according to power fitting equation of the first four experimental data points. Similarly, $\eta_{\infty}$ was estimated by extrapolating at $\omega$ value of $1000 \mathrm{~s}^{-1}$ according to power fitting equation of the last four experimental data points. By defining the relative viscosity as the ratio of $\left(\eta^{*}-\eta_{\infty}\right) /\left(\eta_{o}-\eta_{\infty}\right)$, (5) could be rewritten in a linear form as follows:

$$
\left[\left(\frac{1}{\text { relative viscosity }}\right)-1\right]^{-m}=\lambda \omega \text {. }
$$

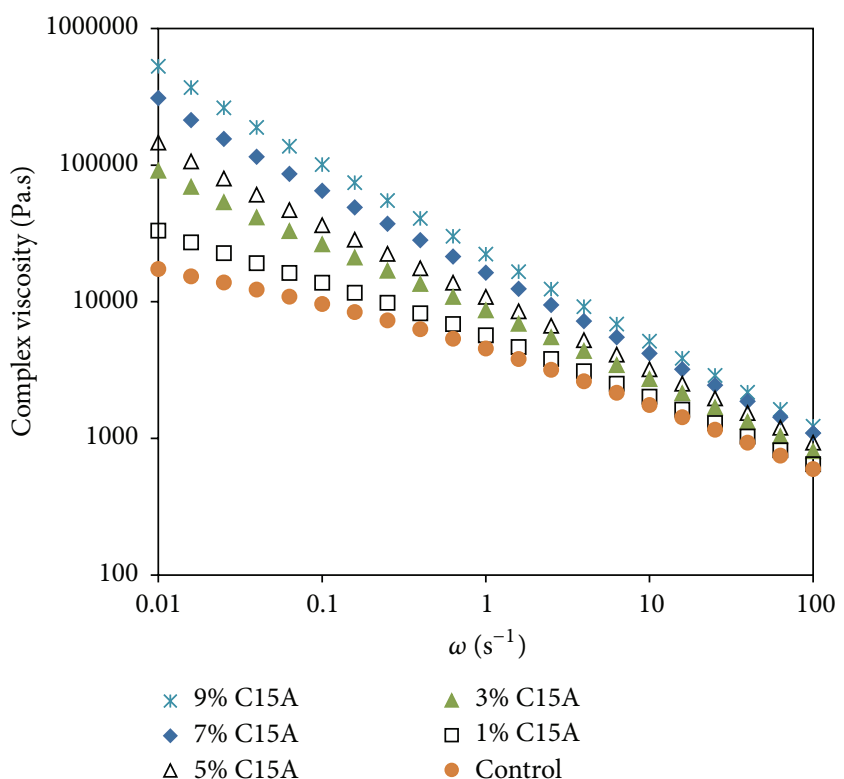

FIGURE 14: Effect of angular frequency and C15A nanoclay loading on the complex viscosity of MAPE matrix (control).

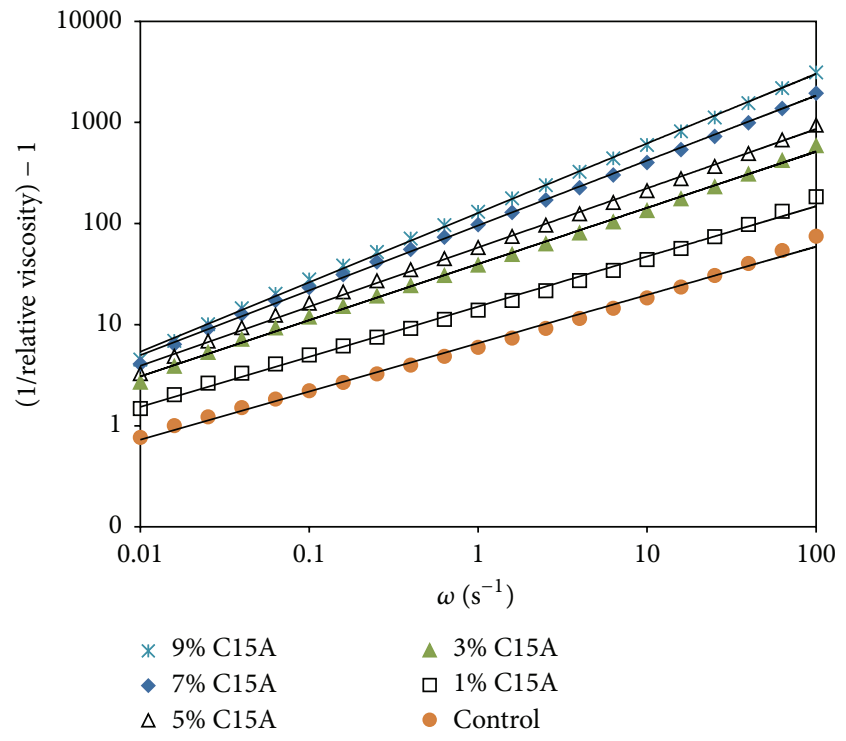

FIGURE 15: Fitting of the complex viscosity data (discrete points) to the Cross model (solid lines) for MAPE matrix (control) filled with C15A nanoclay of different loadings. Parameters of the Cross model were summarized in Table 2.

Therefore, a straight line would be expected by plotting $[(1 /$ relative viscosity $)-1]$ against $\omega$ on a $\log -\log$ scale, and hence the parameters $m$ and $\lambda$ could be obtained directly. After linearization, the fitting of the data with the Cross model was shown in Figure 15, and the Cross model parameters were summarized in Table 2. Straight lines on the log-log scale were observed in Figure 15 with $R^{2}$ values higher than 0.99 , suggesting that there was an excellent fit between the data and the Cross model for the entire range of $\omega$ considered $\left(0.01\right.$ to $\left.100 \mathrm{~s}^{-1}\right)$. As shown in Table $2, m$ was gradually 
TABLE 1: Power law parameters of C15A/MAPE nanocomposites calculated based on the frequency range from 0.1 to $10 \mathrm{~s}^{-1}$.

\begin{tabular}{lccc}
\hline C15A loading & $\begin{array}{c}\text { Shear thinning } \\
\text { index, } n\end{array}$ & $K$ & $R^{2}$ value \\
\hline 0 & 0.370 & 4373 & 0.9958 \\
1 wt.\% & 0.417 & 5521 & 0.9982 \\
3 wt.\% & 0.491 & 8588 & 0.9998 \\
5 wt.\% & 0.527 & 10848 & 1.000 \\
7 wt.\% & 0.594 & 16415 & 1.000 \\
9 wt.\% & 0.646 & 22568 & 1.000 \\
\hline
\end{tabular}

TABLE 2: Cross model parameters of C15A/MAPE nanocomposites calculated based on the entire frequency range from 0.01 to $100 \mathrm{~s}^{-1}$.

\begin{tabular}{lccccc}
\hline C15A loading & $\lambda(\mathrm{s})$ & $m$ & $R^{2}$ value & $\eta_{o}(\mathrm{~Pa} \cdot \mathrm{s})$ & $\eta_{\infty}(\mathrm{Pa} \cdot \mathrm{s})$ \\
\hline 0 & 6.5622 & 0.4772 & 0.9955 & 30572 & 198 \\
1 wt.\% & 15.082 & 0.4962 & 0.9966 & 82146 & 206 \\
3 wt.\% & 39.818 & 0.5556 & 0.9983 & 336832 & 238 \\
5 wt.\% & 57.933 & 0.5855 & 0.9985 & 625463 & 269 \\
7 wt.\% & 95.735 & 0.6420 & 0.9989 & 1578405 & 288 \\
9 wt.\% & 127.58 & 0.6872 & 0.9992 & 2919414 & 296 \\
\hline
\end{tabular}

increased from a value of 0.4772 for the unfilled sample to a value of 0.6872 for the $9 \mathrm{wt} . \% \mathrm{C15A} / \mathrm{MAPE}$ sample, indicating that the shear thinning of the MAPE matrix increased as the loading of $\mathrm{C} 15 \mathrm{~A}$ increased. It was interesting to notice that the shear thinning indices ( $n$ and $m$ ) predicted from both the power law model and the Cross model were in qualitative agreement. Furthermore, as shown in Table 2, the relaxation time $(\lambda)$ of polymer matrix considerably increased as the loading of C15A increased, starting from a value of 6.5622 seconds for the pure polymer to a value of 127.58 seconds for the polymer filled with $9 \mathrm{wt} . \%$ of C15A nanoclay.

\section{Conclusion}

Nanoclay fillers were added to a model polymer matrix, maleated polyethylene (MAPE), in order to study the effect of nanoclay loading on the bulk properties of the nanocomposites prepared. The nanoclays considered were having either hydrophobic surface $(\mathrm{C} 15 \mathrm{~A})$ or hydrophilic surface $(\mathrm{C} 30 \mathrm{~B})$, and the loading of nanoclays was varied from 0 to $9 \mathrm{wt} . \%$. As confirmed by FE-SEM test, tensile mechanical test, and oxidative TGA test, $\mathrm{C} 15 \mathrm{~A}$ was much useful compared to C30B for improving the thermal stability and mechanical properties of the MAPE matrix. Subsequently, XRD test and melt rheology test were done for C15A-filled MAPE samples only. As suggested by XRD, C15A-filled samples had formed nanocomposites structures. This could explain the significant improvement in the oxidative thermal stability and mechanical properties of MAPE upon the addition of $\mathrm{C} 15 \mathrm{~A}$. The rheological percolation threshold was determined to be around $3 \mathrm{wt} . \%$ loading of C15A clay in MAPE matrix. Fitting the viscosity data to the Cross model suggested that the shear thinning index and relaxation time of the prepared nanocomposites increased significantly as the loading of C15A increased.

The above findings coupled with previous literature on development of nanoclay-filled polyethylene systems confirmed the two criteria necessary for obtaining nanocomposites of superior mechanical and thermal properties. The first criterion was the fact that the surface of nanoclays is required to be modified with long alkyl chains similar in structure to polyethylene, such as $\mathrm{C} 15 \mathrm{~A}$ nanoclay. The second criterion was the fact that functionalized polyethylene such as MAPE is required to be present in the system either as the main matrix or as a compatibilizer.

\section{Conflict of Interests}

The author declares that there is no conflict of interests regarding the publication of this paper.

\section{Acknowledgment}

The author would like to acknowledge King Fahd University of Petroleum \& Minerals (KFUPM) for providing all the necessary laboratory and research facilities needed to accomplish this work.

\section{References}

[1] G. Mittal, V. Dhand, K. Y. Rhee, S.-J. Park, and W. R. Lee, "A review on carbon nanotubes and graphene as fillers in reinforced polymer nanocomposites," Journal of Industrial and Engineering Chemistry, vol. 21, pp. 11-25, 2015.

[2] M. Ceraulo, M. Morreale, L. Botta, M. C. Mistretta, and R. Scaffaro, "Prediction of the morphology of polymer-clay nanocomposites," Polymer Testing, vol. 41, pp. 149-156, 2015.

[3] J. Karger-Kocsis, H. Mahmood, and A. Pegoretti, "Recent advances in fiber/matrix interphase engineering for polymer composites," Progress in Materials Science, vol. 73, pp. 1-43, 2015.

[4] C.-W. Chiu, T.-K. Huang, Y.-C. Wang, B. G. Alamani, and J.-J. Lin, "Intercalation strategies in clay/polymer hybrids," Progress in Polymer Science, vol. 39, no. 3, pp. 443-485, 2014.

[5] E. I. Unuabonah and A. Taubert, "Clay-polymer nanocomposites (CPNs): adsorbents of the future for water treatment," Applied Clay Science, vol. 99, pp. 83-92, 2014.

[6] S. Sinha Ray, Clay-Containing Polymer Nanocomposites: From Fundamentals to Real Applications, Elsevier, London, UK, 2013.

[7] T. D. Fornes and D. R. Paul, "Modeling properties of nylon 6/clay nanocomposites using composite theories," Polymer, vol. 44, no. 17, pp. 4993-5013, 2003.

[8] M. R. Schütz, H. Kalo, T. Lunkenbein, J. Breu, and C. A. Wilkie, "Intumescent-like behavior of polystyrene synthetic clay nanocomposites," Polymer, vol. 52, no. 15, pp. 3288-3294, 2011.

[9] M. Frounchi and A. Dourbash, "Oxygen barrier properties of poly(ethylene terephthalate) nanocomposite films," Macromolecular Materials and Engineering, vol. 294, no. 1, pp. 68-74, 2009.

[10] D. Duraccio, A. Mauriello, S. Cimmino et al., "Structureproperty relationships in polyethylene based films obtained by blow molding as model system of industrial relevance," European Polymer Journal, vol. 62, pp. 97-107, 2015. 
[11] A. A. Adesina, A. A. Al-Juhani, N. Tabet, A. Ul-Hamid, and I. A. Hussein, "Rheology and enhancement of extrusion of linear and branched polyethylenes using low amount of organoclay," Journal of Applied Polymer Science, vol. 126, no. 2, pp. 713-723, 2012.

[12] H. Sadeghipour, H. Ebadi-Dehaghani, D. Ashouri, S. Mousavian, M. Hashemi-Fesharaki, and M. S. Gahrouei, "Effects of modified and non-modified clay on the rheological behavior of high density polyethylene," Composites B, vol. 52, pp. 164-171, 2013.

[13] M. A. Osman, J. E. P. Rupp, and U. W. Suter, “Tensile properties of polyethylene-layered silicate nanocomposites," Polymer, vol. 46, no. 5, pp. 1653-1660, 2005.

[14] S. Satapathy and R. V. S. Kothapalli, "Influence of fly ash cenospheres on performance of coir fiber-reinforced recycled high-density polyethylene biocomposites," Journal of Applied Polymer Science, vol. 132, no. 28, pp. 42237-42251, 2015.

[15] M. Pöllänen, S. Pirinen, M. Suvanto, and T. T. Pakkanen, "Influence of carbon nanotube-polymeric compatibilizer masterbatches on morphological, thermal, mechanical, and tribological properties of polyethylene," Composites Science and Technology, vol. 71, no. 10, pp. 1353-1360, 2011.

[16] J. K. Adewole, U. A. Al-Mubaiyedh, A. Ul-Hamid, A. A. Al-Juhani, and I. A. Hussein, "Bulk and surface mechanical properties of clay modified HDPE used in liner applications," The Canadian Journal of Chemical Engineering, vol. 90, no. 4, pp. 1066-1078, 2012.

[17] K. H. Wang, M. H. Choi, C. M. Koo, Y. S. Choi, and I. J. Chung, "Synthesis and characterization of maleated polyethylene/clay nanocomposites," Polymer, vol. 42, no. 24, pp. 9819-9826, 2001.

[18] S. H. Lee, J. E. Kim, H. H. Song, and S. W. Kim, "Thermal properties of maleated polyethylene/layered silicate nanocomposites," International Journal of Thermophysics, vol. 25, no. 5, pp. 1585-1595, 2004.

[19] Y. Xie, D. Yu, J. Kong, X. Fan, and W. Qiao, "Study on morphology, crystallization behaviors of highly filled maleated polyethylene-layered silicate nanocomposites," Journal of Applied Polymer Science, vol. 100, no. 5, pp. 4004-4011, 2006.

[20] M.-K. Chang, "Mechanical properties and thermal stability of low-density polyethylene grafted maleic anhydride/montmorillonite nanocomposites," Journal of Industrial and Engineering Chemistry, vol. 27, pp. 96-101, 2015.

[21] J. A. Lee, M. Kontopoulou, and J. S. Parent, "Time and shear dependent rheology of maleated polyethylene and its nanocomposites," Polymer, vol. 45, no. 19, pp. 6595-6600, 2004.

[22] M. M. Reddy, R. K. Gupta, S. N. Bhattacharya, and R. Parthasarathy, "Structure-property relationship of melt intercalated maleated polyethylene nanocomposites," Korea-Australia Rheology Journal, vol. 19, no. 3, pp. 133-139, 2007.

[23] P. A. Sreekumar, M. Elanamugilan, N. K. Singha, M. A. Al-Harthi, S. K. De, and A. Al-Juhani, "LDPE filled with LLDPE/Starch masterbatch: rheology, morphology and thermal analysis," Arabian Journal for Science and Engineering, vol. 39, no. 12, pp. 8491-8498, 2014.

[24] K. Chrissopoulou and S. H. Anastasiadis, "Polyolefin/layered silicate nanocomposites with functional compatibilizers," European Polymer Journal, vol. 47, no. 4, pp. 600-613, 2011.

[25] N. Dayma and B. K. Satapathy, "Morphological interpretations and micromechanical properties of polyamide-6/polypropylene-grafted-maleic anhydride/nanoclay ternary nanocomposites," Materials \& Design, vol. 31, no. 10, pp. 4693-4703, 2010.
[26] Y. Zare and H. Garmabi, "Thickness, modulus and strength of interphase in clay/polymer nanocomposites," Applied Clay Science, vol. 105-106, pp. 66-70, 2015.

[27] K. Chrissafis and D. Bikiaris, "Can nanoparticles really enhance thermal stability of polymers? Part I: an overview on thermal decomposition of addition polymers," Thermochimica Acta, vol. 523, no. 1-2, pp. 1-24, 2011.

[28] S. N. Bhattacharya, R. K. Gupta, and M. R. Kamal, Polymeric Nanocomposites: Theory and Practice, Carl Hanser, Munich, Germany, 2008.

[29] Y. S. Song, "Rheological characterization of carbon nanotubes/poly(ethylene oxide) composites," Rheologica Acta, vol. 46, no. 2, pp. 231-238, 2006.

[30] R. K. Gupta, V. Pasanovic-Zujo, and S. N. Bhattacharya, "Shear and extensional rheology of EVA/layered silicatenanocomposites," Journal of Non-Newtonian Fluid Mechanics, vol. 128, no. 2-3, pp. 116-125, 2005.

[31] O. Valentino, M. Sarno, N. G. Rainone et al., "Influence of the polymer structure and nanotube concentration on the conductivity and rheological properties of polyethylene/CNT composites," Physica E: Low-Dimensional Systems and Nanostructures, vol. 40, no. 7, pp. 2440-2445, 2008.

[32] Y. H. Hyun, S. T. Lim, H. J. Choi, and M. S. Jhon, "Rheology of poly (ethylene oxide)/organoclay nanocomposites," Macromolecules, vol. 34, no. 23, pp. 8084-8093, 2001.

[33] P. Pötschke, T. D. Fornes, and D. R. Paul, "Rheological behavior of multiwalled carbon nanotube/polycarbonate composites," Polymer, vol. 43, no. 11, pp. 3247-3255, 2002.

[34] A. Ponton, C. Meyer, G. Foyart, L. Aymard, and K. Djellab, "Structural and thermomechanical investigation of lyotropic liquid crystal phases doped with monodisperse microparticles," Applied Rheology, vol. 24, no. 1, Article ID 14147, 7 pages, 2014. 

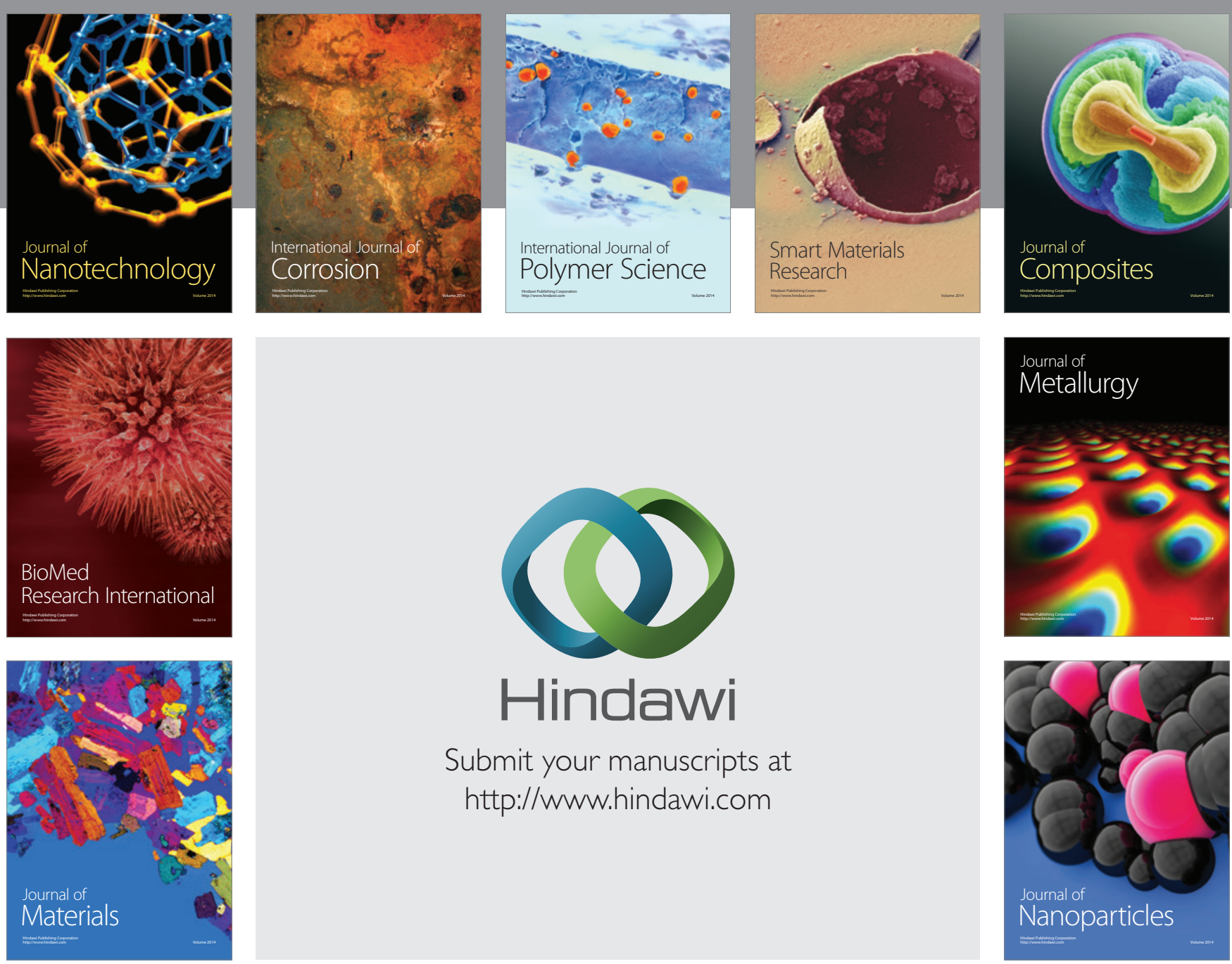

Submit your manuscripts at http://www.hindawi.com
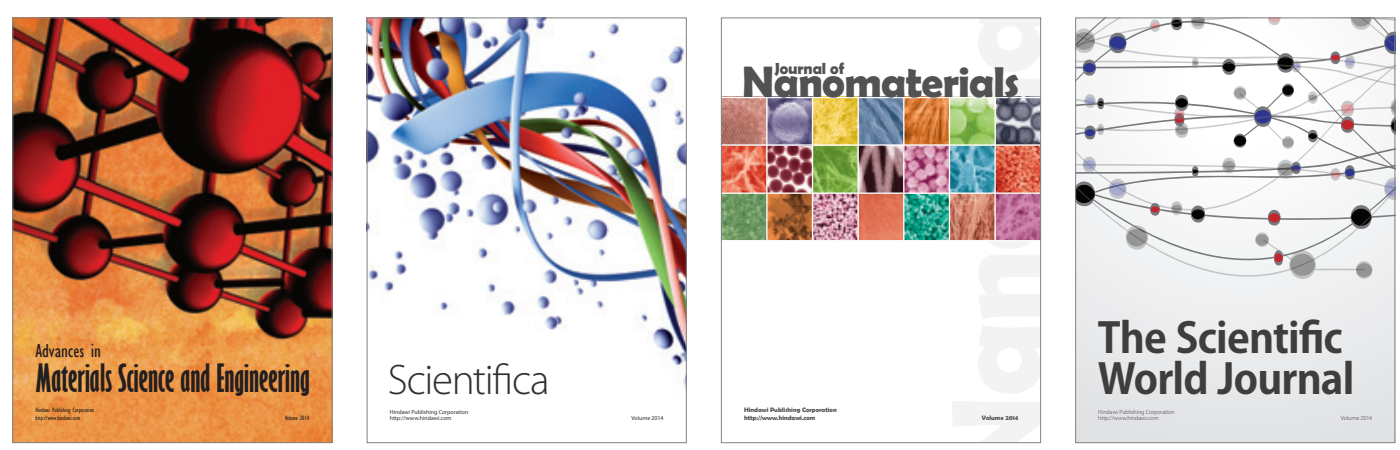

\section{The Scientific World Journal}
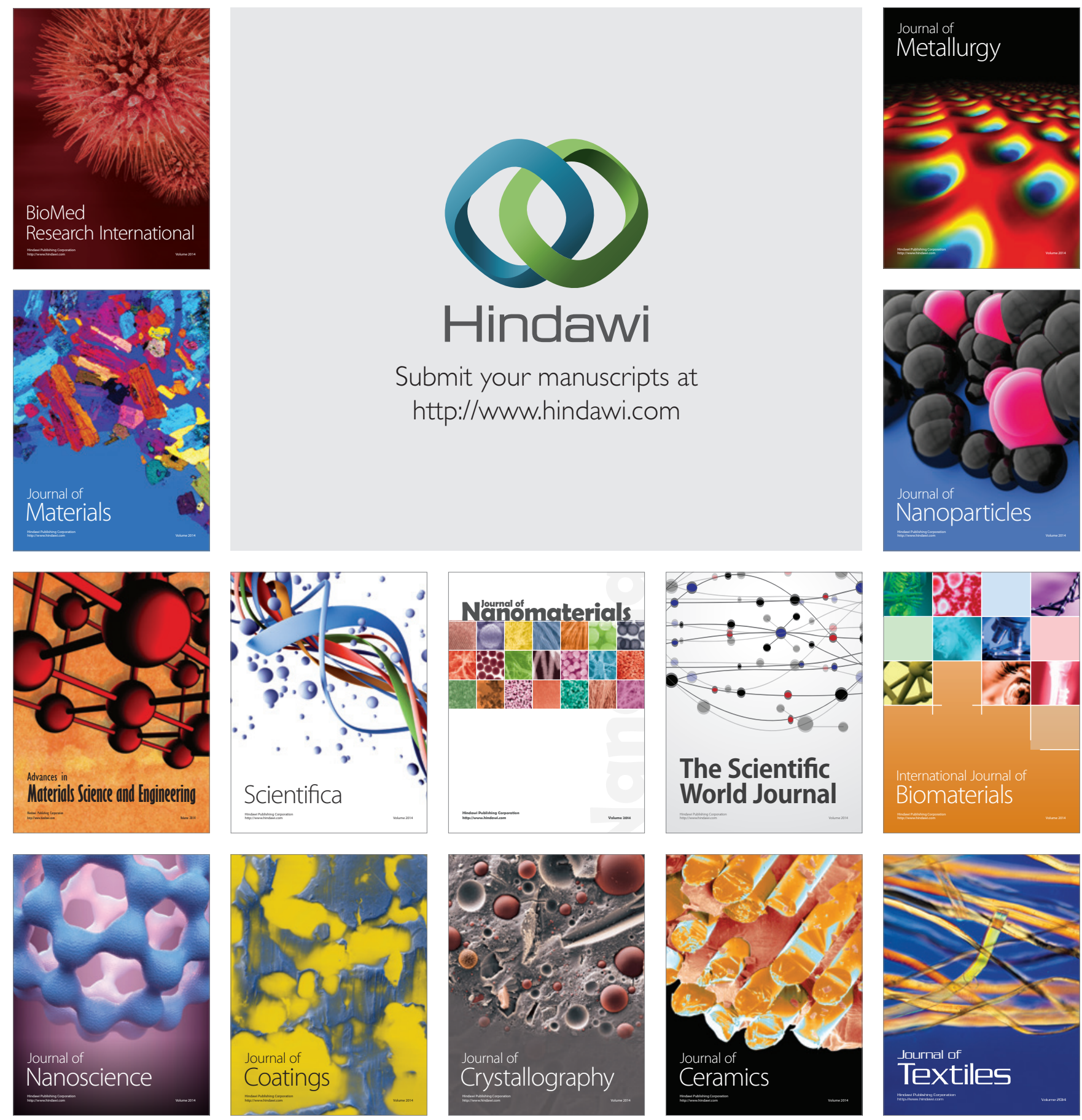